\title{
Chronic histiocytic intervillositis- a rare placental cause of poor obstetric outcome: a clinicopathological study and literature review
}

\author{
Ramya $T^{1}$, Chaitra $\mathbf{V}^{2}$, Umamaheswari $\mathbf{G}^{2}$
}

\author{
${ }^{1}$ Department of Obstetrics \& Gynaecology, PSG Institute of Medical Sciences \& Research, Coimbatore-641004, Tamil \\ Nadu, India \\ ${ }^{2}$ Department of Pathology, PSG Institute of Medical Sciences \& Research, Coimbatore-641004, Tamil Nadu, India
}

Received: 29 September 2014

Accepted: 1 November 2014

\section{*Correspondence:}

Dr. Ramya T,

E-mail: ramya.t2003@gmail.com

Copyright: $\odot$ the author(s), publisher and licensee Medip Academy. This is an open-access article distributed under the terms of the Creative Commons Attribution Non-Commercial License, which permits unrestricted non-commercial use, distribution, and reproduction in any medium, provided the original work is properly cited.

\begin{abstract}
Chronic histiocytic intervillositis (CHIV) of the placenta is a rare and poorly understood entity which may occur in all trimesters of pregnancy. Till date about 60 cases of CHIV has been reported, with high rate of recurrences in subsequent pregnancies. There is increased risk of perinatal mortality and fetal growth restriction in this group, hence diagnosing CHIV becomes important to predict the outcome of subsequent pregnancies and also to understand the pathogenesis, thus treatment choices. Here in, we present a case of CHIV in a primigravida with second trimester pregnancy loss.
\end{abstract}

Keywords: Chronic histiocytic intervillositis, Rare recurrent placental pathology, Perinatal mortality, Fetal growth restriction

\section{INTRODUCTION}

Chronic histiocytic intervillositis (CHIV), is a relatively uncommon and poorly understood condition, characterized by mononuclear cell infiltrate in the intervillous space which is of maternal origin. In addition there can be villous and perivillous fibrin deposition and focal villitis. As CHIV has high association with placental insufficiency, poor perinatal outcome ${ }^{2,3}$ and high recurrent rate in subsequent pregnancies, ${ }^{4,5}$ recognition of this entity is clinically important. The exact incidence of CHIV is unknown but studies conducted by Boyd et al. ${ }^{4}$ and Doss et al. ${ }^{3}$ have revealed incidence to be $6 / 10000$ placentas analyzed in the second and third trimesters, and $4.4 \%$ in placentas of first trimester abortion.

The etiology of CHIV remains obscure. Presence of maternally derived mononuclear cells in the intervillous space has led to the hypothesis that an immune mechanism is involved in the pathogenesis of placental lesions. ${ }^{4}$ Immunosuppressive and thrombolytic treatment has been proposed ${ }^{4,5}$ as a treatment to prevent recurrent CHIV in order to ameliorate the obstetric outcome, but the efficacy is unproven.

\section{CASE REPORT}

A 22 year old primi, conceived with ovulation induction, was booked at 13 weeks of pregnancy. On investigation she was found to be hypothyroid and was started on low dose thyroxin. On subsequent visits she was also found to have mild glucose intolerance and was advised diabetic diet with metformin $500 \mathrm{mg}$ per day. First and second trimester ultrasound examinations were normal and did not reveal any congenital anomalies.

At 24 weeks of pregnancy, she came with the complaints of spotting, absent fetal movements and labour pain. On admission, she was in active labour. USG examination revealed absence of fetal heart activity, confirming intrauterine death. Simultaneously her blood 
investigations revealed total count of 17000 cells/cumm and elevated ESR. Tests for TORCH infections, HIV, HBV, HCV, VDRL and malarial parasites were negative. She delivered a dead male fetus of $460 \mathrm{gm}$. Since the parents were not willing for fetal autopsy, placenta alone was sent for histopathological examination. However external examination of the fetus did not reveal any gross abnormality. ANA and APLA work up were advised on follow up.

The placenta weighed $111.0 \mathrm{gm}$ (small for gestational age, $<10^{\text {th }}$ percentile). There was a smaller lobe measuring $3.3 \times 2.5 \times 1.0 \mathrm{~cm}$ (succenturiate lobe)) which was connected to the larger lobe $(9.5 \times 8.0 \times 2.0 \mathrm{~cm})$ by thickened membranous tissue (Figure 1). The fetal and maternal surfaces were unremarkable. The parenchyma was pale brown, spongy. The umbilical cord was white, $36.5 \mathrm{~cm}$ long, $1.0 \mathrm{~cm}$ diameter, hypocoiled with 5 twists, all to the left, had 3 vessels on the cut surface and one varix. It was inserted into the membranes, $1.0 \mathrm{~cm}$ from the disc margin, was furcated with one of the branches entering the accessory lobe (Figure 2). The membranes were inserted marginally, pale brown and the site of rupture was $3.0 \mathrm{~cm}$ from the disc margin.

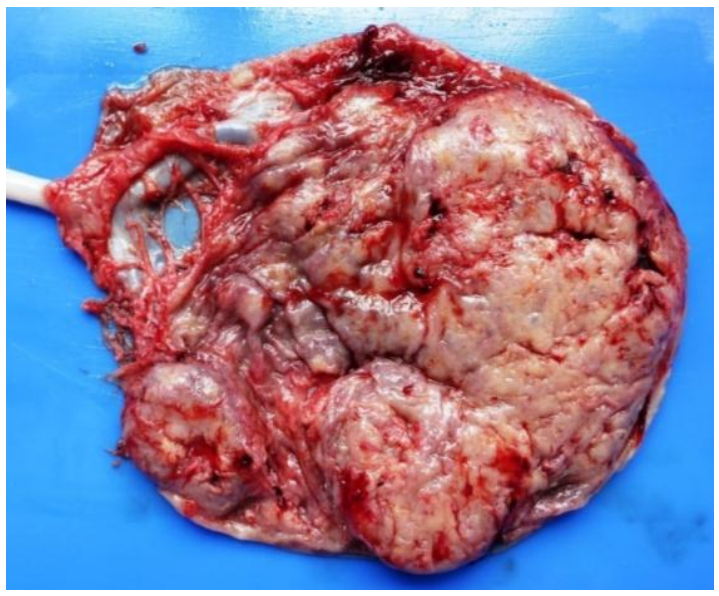

Figure 1: Gross picture of placenta shows succenturiate lobe (arrow) which is separated by larger lobe by thickened membranous tissue.

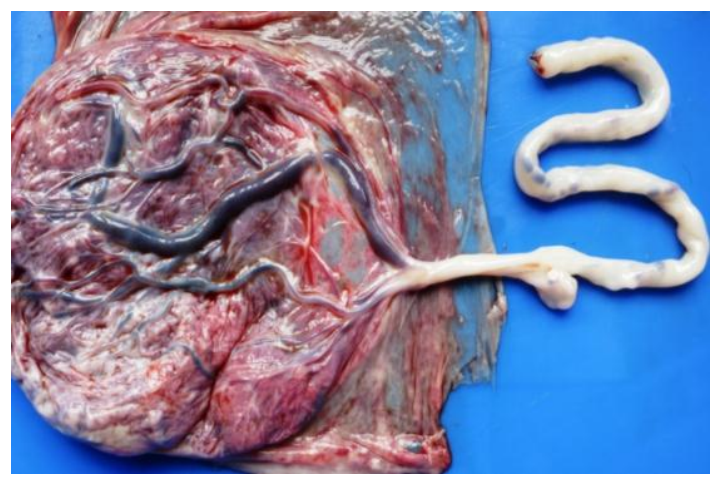

Figure 2: Shows velamentous cord insertion with bifurcation of vessels within the membranous tissue. Umbilical cord shows a varix.
Multiple bits were taken from the umbilical cord, membrane roll, parenchyma of smaller and larger lobes.

Microscopically the velamentous insertion of the cord was confirmed. The amnion and chorion were normal. The decidua of the membrane roll showed a focal moderate mononuclear infiltrate and multinucleate chorionic trophoblasts. Large portions of the intervillous space were filled with mononuclear cells, mainly histiocytes (Figure 3). The villi in these areas showed loss of trophoblastic cover and were surrounded by fibrin with nuclear debris. Immunohistochemical stain showed CD68 positivity in these mononuclear cells, thus confirming their histiocytic nature (Figure 4). The syncytiotrophoblasts showed nuclear pyknosis and 'ghost nuclei'. The basal plate showed a moderate lymphohistiocytic infiltrate. A few groups of hyalinized and avascular villi were seen, but there was no significant villous inflammation. There were no viral inclusions/malarial pigment. Hence a diagnosis of chronic histiocytic intervillositis in second trimester placenta was offered.

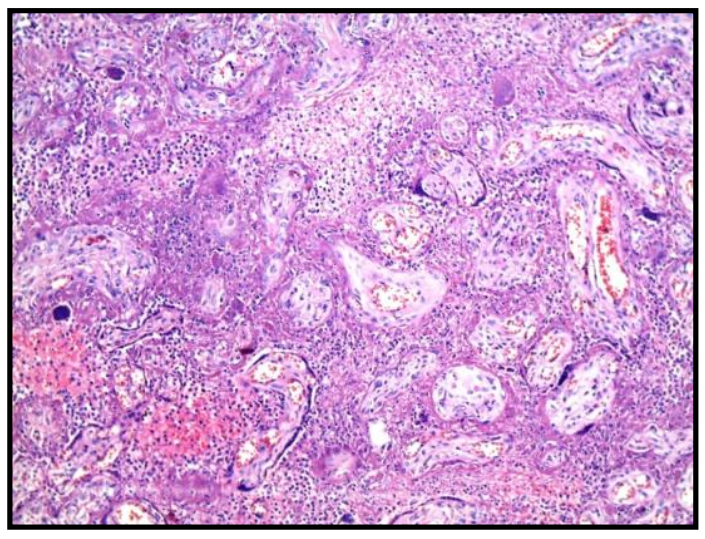

Figure 3: Figure 3: Sections from parenchyma shows villi with expanded intevillous spaces, which are filled with inflammatory cells. Many of the chorionic villi show loss of trophoblastic lining (H\&E, 10x). Inset shows the nature of the infiltrate $(40 x)$.

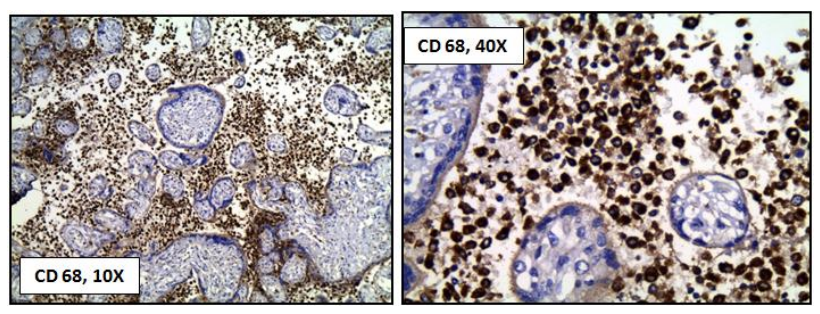

Figure 4: Mononuclear cells in the intervillous spaces show strong cytoplasmic positivity for CD68 (Immunohistochemical stain).

\section{DISCUSSION}

CHIV was initially described in 1987 by Labarrere and Mullen ${ }^{1}$ for the placental lesion that showed massive chronic inflammation in intervillous spaces associated 
with fibrinoid and trophoblastic necrosis. They thought it to be a variant of villitis of unknown etiology. It is also known by other names: chronic intervillositis of unknown etiology (CIUE), chronic intervillitis.

CHIV is usually found in patients with severe obstetric complications like early spontaneous abortions, late abortion, preterm deliveries, severe IUGR, intrauterine deaths and has a high rate of recurrences $(60-80 \%)^{12}$ in subsequent pregnancies. There are no clinical features that are specific to and predict CHIV. But a study by V. Marchaudon et al. ${ }^{13}$ has shown elevated maternal alkaline phosphatase levels in more than $50 \%$ of their cases. Further studies needs to be conducted to validate the same as alkaline phosphatase being an isoenzyme is elevated in many other conditions.

CHIV is a histopathologic diagnosis characterized by the presence of mononuclear infiltrate in intervillous spaces which are CD68 positive. ${ }^{15}$ Intervillous inflammatory infiltrate are also noted in women with malaria, listeriosis, tularemia, coccidiomycosis, viral and rickettsial infections. In above mentioned conditions the infiltrate are either acute or mixed inflammatory cells. One should look for presence of viral inclusions, malarial pigment, bacteria and nature of inflammatory infiltrate before making a diagnosis of CHIV.

The exact etiology of histiocytic intervillositis is not known, articles about it are sparse. ${ }^{1-6}$ Some authors ${ }^{7-9}$ have suggested that maternal immune reaction may be directed against the paternally derived antigens of the fetus mediated by maternal mononuclear cells, kind of graft rejection. ${ }^{2,11}$ This immune aggression may occur because of the failure of regulatory mechanisms that should protect the pregnancy throughout gestation ${ }^{3,4}$. Overall, it has been proposed that the mechanism of CHIV may be based on an immune phenomenon of an unknown nature that causes histiocytes to flow into the intervillous space, lesions to occur in the syncytial cells, and finally syncytial coverage by fibrin deposits that progressively impair maternofetal exchanges. An association with antiphospholipid antibodies has been reported, ${ }^{14}$ validating the hypothesis of an immunological mechanism underlying this condition.

Immuno suppressive therapy and thrombolytic treatment has been proposed ${ }^{2,4,5}$ to prevent recurrent CHIV. Prednisolone, aspirin, heparin and progesterone were used alone or in combinations. Although various different combinations were used, the livebirth rate reported with treatment was $30 \%$ against $58.9 \%$ without treatment. ${ }^{10}$ This difference was not statistically significant. Hence further studies need to be conducted to understand the pathophysiology and treatment choices.

\section{CONCLUSION}

It is important to recognize this rare placental pathology. Chronic histiocytic intervillositis has a big impact on the reproductive capacity of a woman, being associated with pregnancy losses, growth restriction and adverse perinatal outcome. The condition has a very high recurrence rate. Availability of an intervention to prevent a recurrence is an attractive proposition, but there are no controlled trials in CHIV. This is possibly because the lesion is rare, and also because it can only be diagnosed after delivery.

\section{ACKNOWLEDGEMENTS}

We acknowledge the services of Dr. Ammu Srinivasan, Emeritus Professor, Department of Pathology, PSGIMSR.

Funding: No funding sources

Conflict of interest: None declared

Ethical approval: Not required

\section{REFERENCES}

1. Labarrere C, Mullen E. Fibrinoid and tropholastic necrosis with massive chronic intervillositis: an extreme variant of villitis of unknown etiology. Am J Reprod Immunol Microbiol. 1987;15:85-91.

2. Jacques SM, Qureshi F. Chronic intervillositis of placenta. Arch Pathol Lab Med. 1993;117:1032-5.

3. Doss BJ, Greene MF, Hill J, Heffner LJ, Bieber FR, Genest DR. Massive chronic intervillositis associated with recurrent abortions. Hum Pathol. 1995;26:124551.

4. Boyd TK, Redline RW. Chronic histiocytic intervillositis: a placental lesion associated with recurrent reproductive loss. Hum Pathol. 2000;31:1389-96.

5. Parant O, Capdet J, Kessler S, Aziza J, Berrebi A. Chronic intervillositis of unknown etiology (CIUE): relation between placental lesions and perinatal outcome. Eur J Obstet Gynaecol Reprod Biol. 2009;143:9-13.

6. Rota C, Carles D, Schaeffer V, Guyon F, Saura R, Horovitz J. Perinatal prognosis of pregnancies complicated by placental chronic intervillitis. J Gynaecol Obstet Biol Reprod (Paris). 2006;35:711-9.

7. Redline RW. Placental inflammation. Semin Neonatal. 2004;9:265-74.

8. Kraus F. Placental pathology, inflammation and infection. In: American Registry of Pathology, eds. Atlas of Non Tumour Pathology. Washington: AFIP Collection; 2004: 36, 101-107, 135-140.

9. Nessman CLJ, Jauniaux E. Maternal immune reaction. In: Nessman CLJ, Jauniaux E, eds. Atlas de pathologie placentaire. US: Elsevier-Masson; 2001: $1-156$.

10. Traeder J, Jonigk D, Feist H, Bröcker V, Länger F, Kreipe $\mathrm{H}$, et al. Pathological characteristics of rare chronic histiocytic intervillositis of the placenta. Placenta. 2010;31:1116-9.

11. Dollmann A, Schmitz-Moormann P. Recurrent placental insufficiency due to villous placentitis with extreme growth retardation (birth weights $1030 \mathrm{~g}$. 
and 1000 g. at term). Geburstshilfe Frauenheilkd. 1972;32:795-801.

12. Contro E, DeSouza R, Bhide A. Chronic intervillositis of placenta: a systematic review. Placenta. 2010;31:1106-10.

13. Marchaudon V, Devisme L, Petit S, Ansart-Franquet H, Vaast P, Subtil D. Chronic histiocytic intervillositis of unknown etiology: clinical features in a consecutive series of 69 cases. Placenta. 2011;32:140-5.
14. Salafia CM, Cowchock FS. Placental pathology and antiphospholipid antibodies: a descriptive study. Am J Perinatol. 1997;14:435-41.

15. Debra S. Heller. CD68 immunostaining in the evaluation of chronic histiocytic intervillositis. Arch Pathol Lab Med. 2012 Jun;136(6):657-9.

DOI: $10.5455 / 2320-1770$. ijrcog20141258

Cite this article as: Ramya T, Chaitra V,

Umamaheswari G. Chronic histiocytic intervillositisa rare placental cause of poor obstetric outcome: a clinicopathological study and literature review. Int J Reprod Contracept Obstet Gynecol 2014;3:1146-9. 